\title{
The developing female chorister voice: case-study evidence of musical development
}

\author{
David M Howard(1), Graham F Welch(2), Evangelos Himonides(2) \\ and Matthew Owens(3) \\ (1) Department of Electronic Engineering, Royal Holloway, University of London, UK \\ (2)UCL Institute of Education, University College London, UK \\ (3) Organist and Master of the Choristers of Wells Cathedral, UK
}

\begin{abstract}
The human singing voice changes throughout the lifespan and there are genderspecific variations that need to be taken into account. Life changes in terms of voice are different for females and males and this paper concentrates on the female singing voice in the context of choral singing. Case-study data from three choristers are presented relating to the changing female voice during puberty as part of a longitudinal study of female choristers in a major English Cathedral Choir School. In addition, discussion is presented on important considerations with respect to the female choral singing voice with a particular focus on specific choral aspects during rehearsals and performance.
\end{abstract}

Keywords: Singing, choral, performance, chorister, girls

\section{Introduction}

Singing is something that provides great pleasure and satisfaction to many people, whether they sing in the privacy of their own home, sing in a choir or sing individually in public audiences $[c f 1,2]$. For many such singers, singing is simply something that they can do without necessarily realising that, with some added knowledge, vocal improvements could probably be made quite readily, such as through the application of established craft knowledge and research evidence [e.g. 3, 4].

Our understanding of the way in which the human voice works in terms of its underlying anatomy and physiology, how best to 'play' the voice as an 'instrument and the nature of the resulting acoustic output, has moved on hugely over the last 2030 years. This is primarily a result of the ubiquity of personal computers (PCs) and their ability to carry out acoustic signal analyses fast enough to enable real-time displays to be presented on-screen when singing. Many young singers now expect to make use of their portable computers and other portable technology in their everyday lives, which they include as a part of their voice training as a means to understand better the underlying principles of voice physiology and voice acoustics [5, 6].

There are male-female differences that are important in the context of the singing voice, particularly in terms of the pitch ranges covered, some of the voice qualities that are employed in performance and the absolute sounds of the vowels produced as a result of differing female-male vocal tract sizes [7]. These are important in terms of 
intonation and blend - two core aspects of improving excellence in choral performance.

\section{Acoustics of the female singing voice}

The human singing voice can be considered in terms of three elements [8]:

- the power source

- the sound source; and

- the sound modifiers.

These three elements relate to the physiology of the vocal instrument as well as being a basis upon which their individual contributions to the overall acoustic output can be considered.

The power source provides the energy for vocal sound production and - in singingthis is the control of airflow from the lungs, which in turn, affects the nature of the acoustic output from the vibrating vocal folds. Developing an appropriate breathing technique is basic to a good singing technique, but is beyond the scope of this article; further information can be found in Watson (2014)[9].

The sound source for pitched notes is the vibrating vocal folds within the larynx. Their regular vibration at a controlled rate results in an acoustic output that is perceived at a specific pitch (related to fundamental frequency or f0). For example, if a singer's vocal folds are vibrating 440 times a second, they are singing the note A above middle $\mathrm{C}$ (usually indicated as $\mathrm{A} 4$ ). A pitch increase of an octave results in a doubling of the f0 of vocal fold vibration, so when a soprano sings the note A5 (an octave above the A4 discussed earlier), her vocal folds are vibrating 880 times a second, usually indicated as $880 \mathrm{Hertz}$ or $880 \mathrm{~Hz}$. Because the sung vocal ranges of female singers are very approximately between a sixth and an octave above those of male singers, a female singer's vocal folds will vibrate up to twice as rapidly as her male counterpart. Noting that the vibrating vocal folds are colliding at their midline in every vibration (which is what causes the acoustic excitation to the vocal tract in singing and speaking and is often quite reasonably compared to a hand clap [e.g. 10]), indulging in healthy vocal practice is particularly important.

Assured control of the vibration of the vocal folds is critical for holding a note at a steady pitch. Overall control of pitch is a skill to be attained by a singer when singing the different notes of a melody by changing pitch (changing the vibration rate of the vocal folds), changing the overall loudness of a note to create musical dynamic variations from pianissimo ( $p p)$ to fortissimo $(f f)$, increasing or decreasing the amount of vibrato (pitch undulation), as well as starting and ending notes while maintaining their pitches throughout, no matter what text is set to the note.

In addition, there are major variations between females and males during voice change from before to during puberty [e.g. 11-13]. At this point in the lifespan, there are major physical changes, and - in the case of voice production in speech as well as singing - it is the larynx that changes considerably in size [14]. Given that the larynx is the sound source in singing and speech, changes in its overall size cause significant changes in the nature of its acoustic output [15]. In pre-puberty, the female and male 
larynxes are approximately the same size. Pubertal change results in the vocal folds of boys increasing in length by over double that of girls [16].

Pitch control develops with age and experience and it starts when we learn to speak as we take on board the intonation of the language that surrounds us, mostly at home [17]. Singing with someone else poses a different scenario in that the starting note to sing is likely to be set by an external pitch reference, such as an individual note from a piano, or other instrument, or another voice. For a small proportion of people, making the link with an external pitch reference and getting the starting note (and other notes) in-tune is a really difficult thing to do, and often this is referred to (completely inappropriately in our view) as being 'tone deaf'. More appropriate labels within the literature are 'poor pitch singer' (from a psychoacoustic perspective) or, perhaps better, 'developing singer' (from an educational perspective).

This relative inability to sing in-tune can be changed and with some guidance and practice on pitch focussing to an external reference note as opposed to the internalised pitch reference used when speaking; there is nothing to prevent in-tune singing ability from flourishing [18-21]. Furthermore, a landmark study seeking to understand singing proficiency in the general adult population [22] reported that the majority of adult participants could, when prompted, sing a recognisable tune from memory with relatively few pitch deviations. Furthermore, these adult participants - termed 'occasional singers' - were more pitch accurate if they performed the well-known target melody at slower tempi, being generally as accurate as a comparison group of professional singers.

\section{A brief history of female choristers in English cathedral choirs ${ }^{1}$}

Choral activity has been part of the daily ritual in cathedrals, minsters ${ }^{2}$ and major chapels ${ }^{3}$ across the United Kingdom since the foundation of the first Benedictine abbey by St Augustine at Canterbury in 597 AD. Subsequently, the Canterbury model of religious foundation was repeated at Rochester (604 AD), London (St. Paul's) (604 AD) and York (627 AD). On entry to a religious foundation as a novitiate, an individual's new identity would be marked by a change in appearance (such as through special clothing - the 'habit' - and tonsured hair styling for boys, or perhaps the wearing of a ring to demonstrate betrothal to Christ for girls ${ }^{4}$ ). In the relatively closed environment of the monasteries (compared to the more secularly organised cathedrals ${ }^{5}$ ), children would have had little subsequent contact with their family [25].

\footnotetext{
${ }^{1}$ The following text draws on an extended review of the recent re-introduction of female choristers in the English cathedrals [23].

${ }^{2}$ Minsters are large and important churches that have the status of cathedrals and that were customarily part of a monastery.

${ }^{3}$ Depending on their original foundation status, there are three major categories of religious institution in the UK that have choristers. The vast majority are cathedrals, with a very small number of Abbeys and a few so-called 'Major Chapels' (such as at King's College, Cambridge). Throughout this article, the term 'cathedrals' is used as a collective term to signify this overall set of broadly similar settings for the performance of religious choral music.

${ }^{4}$ When taking their religious vows, young women wore white, as in a marriage ceremony, and had a ring placed in their finger [24 p24].

${ }^{5}$ By the $12^{\text {th }}$ Century, nine of England's seventeen cathedrals were secular with boy choristers [25 p.23]. Each cathedral was (and is) managed by its own staffing 'Foundation', headed by a 'Dean' with support from a small number of appointed 'Canons'. Religious activity is managed on a regional basis
} 
A central part of the children's education and induction into religious life would have included the singing of the daily liturgy (e.g. mass, lauds, vespers, psalms) by the quire (q.v. choir) [24]. Some monastic buildings had an adjacent cathedral (the seat of the Bishop - such as at Canterbury) and all would have had their own quire.

Nationally, by the time of the plague associated with the Black Death (1348-1349), it is estimated that there were over 1,000 monasteries and nunneries across Britain, embracing 14,000 monks and 3,000 nuns [26]. Customarily, these religious foundations would have had boys (in the monasteries and a few nunneries) and girls (in the nunneries) who were involved in the musical life and daily worship. In contrast, music in the cathedrals would have continued to be all male. The English Reformation in the $16^{\text {th }}$ Century saw the dissolution of the monasteries and relatively few opportunities for girls to be part of a rich sacred music culture until the late $20^{\text {th }}$ Century $^{6}$, when girls' choirs began to be re-introduced, the first being at Salisbury in 1991 [23]. The majority of cathedrals now have both girls' and boys' choirs, usually singing separately on alternate days of the week, and brought together for special events, such as at Christmas [27].

\section{Development of sound source control in the female choir voice}

The ability to control pitch in a manner appropriate for choral singing involves a degree of control over the vibration of the vocal folds that is greater than during speech in terms of the requirements of the singing of individual notes and changing between notes in a musical manner. In addition, the pitches of individual notes have to be maintained during any consonants associated with the words being sung when those consonants are themselves voiced or pitched (such as those in "me", "no", "love", "ding", "rang", "bring” and "though").

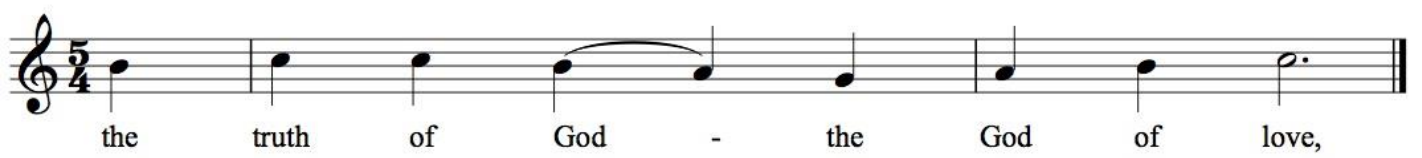

Figure 1: Score as sung for the recordings of the second line ("the truth of God the God of love") of the carol "This is the truth sent from above".

The research aim was to observe and explore continuities and changes in the pitch control of the developing female voice related to the context of a professional cathedral choir in the UK. As part of an ongoing study, case study example f0 analyses of a series of four recordings for each of three Wells cathedral girl choristers - taken between May 1999 and May 2006 - are presented. All three were choristers in the choir at the time of the first recording and two (NZKM and FWAH) continued to be choristers throughout this data collection period. MJRM was an ex-chorister for the final two recordings, but still singing regularly. The dates of the recordings for each

across the country, with each region — or 'diocese' — being headed by a Bishop whose 'throne' ('cathedra' $($ Latin) $=$ chair, one of the symbols of office) is located within a cathedral.

${ }^{6}$ Salisbury cathedral's introduction of funded choral scholarships for girl in 1991 had a large media impact at the time because this was seen as a novel action for one of the oldest cathedrals in England. However, St David's Cathedral, Wales and St Mary's Episcopal Cathedral, Edinburgh, Scotland had previously included girl choristers in their choirs. In England, St Edmundsbury, Leicester and Manchester cathedrals had included girl choristers, but these were built originally as parish churches and were awarded cathedral status in relatively modern times. 
chorister are given in table 1, spanning 5 years for chorister NZKM, and 4.5 years for choristers MJRM and FWAH. During these recording sessions, a standard recording protocol was employed that included a read passage, spoken and sung isolated vowelconsonant-vowel utterances, a two-octave $\mathrm{G}$ major scale and a sung verse of the carol "This is the truth sent from above" or if this was not known the nursery rhyme "Baa, baa, black sheep". Ethical procedures were followed in line with the expectations of the British Educational Research Association (BERA) and according to the equivalent safeguarding requirements for pupils of the cathedral school. All the recordings were made in a quiet space, familiar to the participants, with a fixed subject to microphone distance.

For the purposes of the analyses presented herein, all three choristers each sang a verse from the carol "This is the truth sent form above".

\begin{tabular}{|l|l|l|l|l|l|}
\hline chorister & age at start & recording 1 & recording 2 & recording 3 & recording 4 \\
\hline NZKM & $12 \mathrm{y} 2 \mathrm{~m}$ & May 1999 & May 2001 & May 2003 & June 2004 \\
\hline MJRM & $13 \mathrm{y} 0 \mathrm{~m}$ & October 2001 & October 2003 & October 2005 & May 2006 \\
\hline FWAH & $10 \mathrm{y} 2 \mathrm{~m}$ & October 2001 & May 2003 & October 2005 & May 2006 \\
\hline
\end{tabular}

Table 1: Recording dates for the four recordings of the three choristers and their ages at the time of the first recording; dates in bold indicate continued cathedral choir membership.

To explore changes in pitch control, the second line ("the truth of God the God of love") of the carol "This is the truth sent from above" has been used; its score is shown in Figure 1. Four f0 plots are shown in Figure 2 across the overall time range of the recordings for each chorister. Note that (a) the $\mathrm{Y}$-axis is in cents (100 cents is one semitone) above F4, so the starting note (B4) is plotted at 600 cents since B4 is 6 semitones above F4, and (b) the $\mathrm{X}$-axis (the time in seconds) varies for each plot since the tempo for their performance was left to the singer's discretion. Pitch reference for the starting pitches was provided by an electronic keyboard. 
May-99 (NZKM)
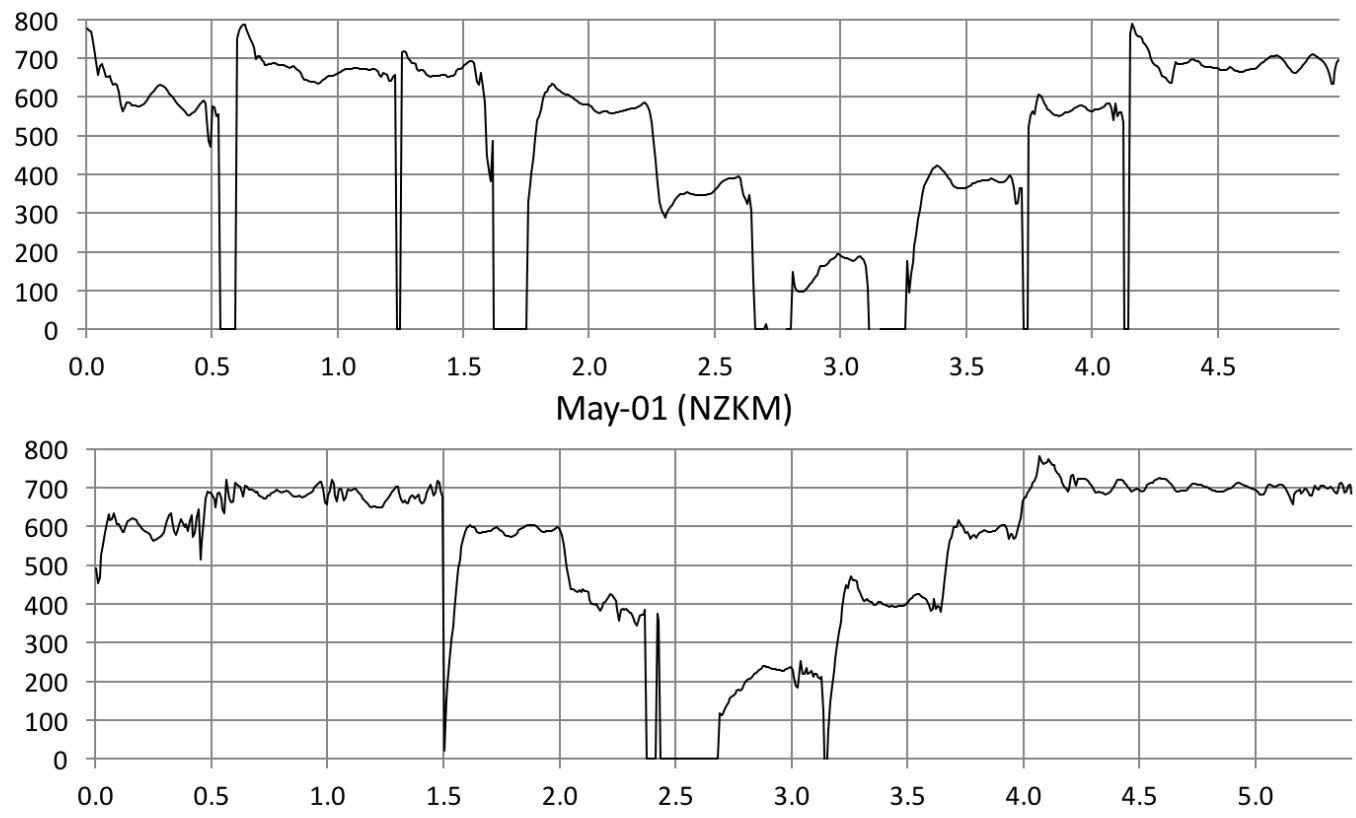

May-03 (NZKM)
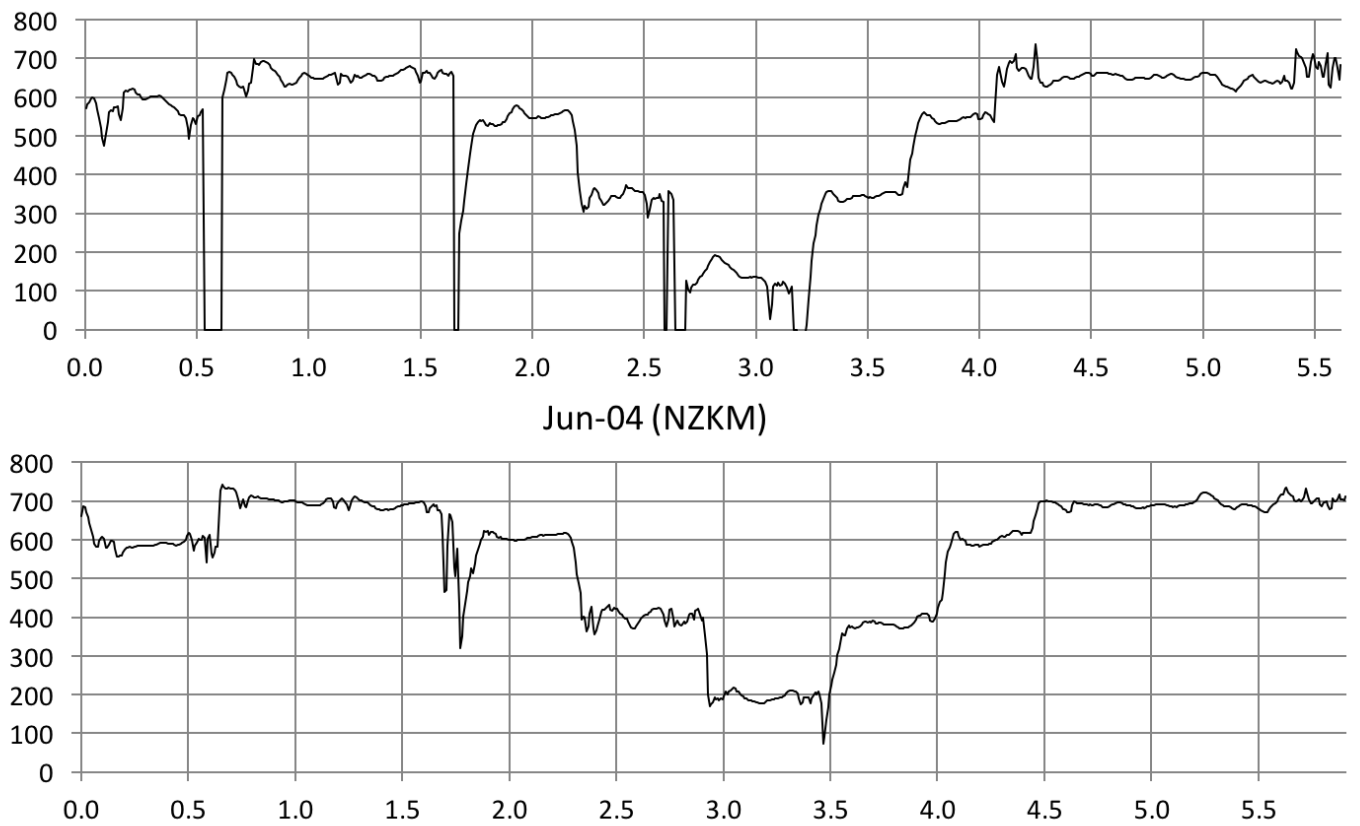
Oct-01 (MJRM)
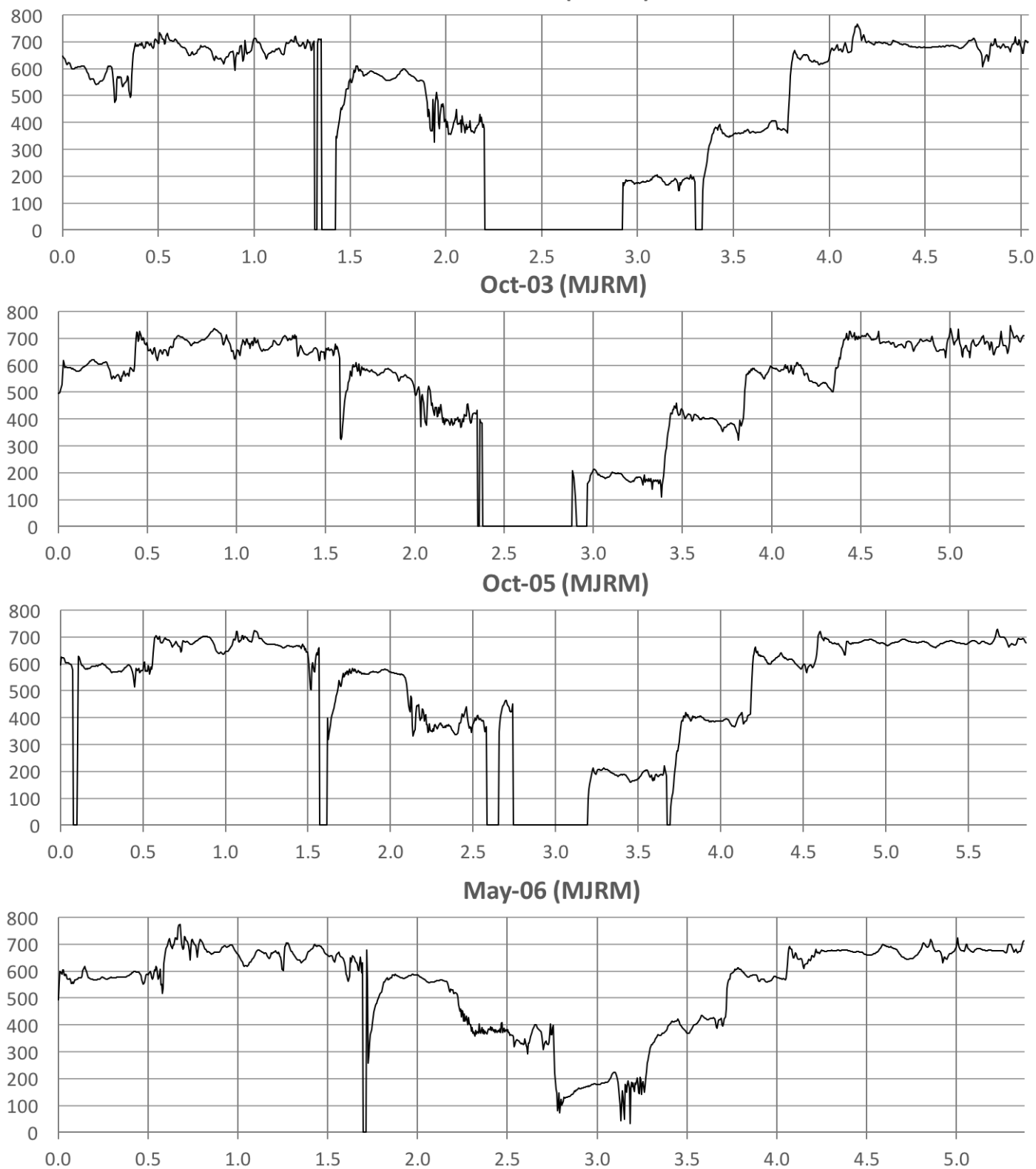

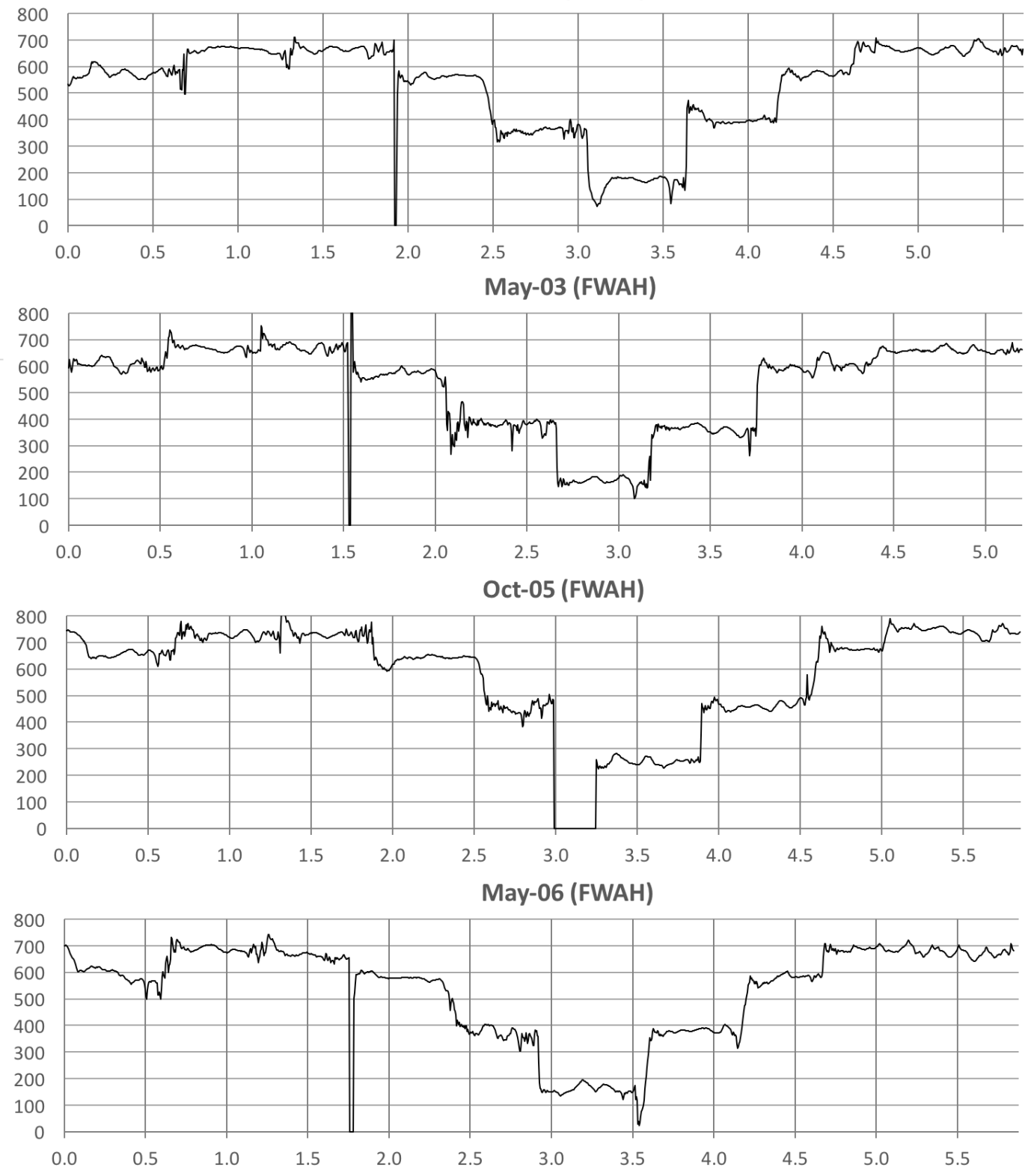

Figure 2: Fundamental frequency (f0) contours for four sung renderings by three individual female cathedral choristers of 'the truth of God the God of love' (the second line of 'This is the truth from above' - score shown in figure 1) at the recording dates shown. Note that (a) the X-axis (the time in seconds) varies for each plot since the tempo for their performance was left to the singer's discretion, and (b) the $\mathrm{Y}$-axis is in cents (100 cents is one semitone) above F4, so the starting note of this second line (B4 - see figure 1) is plotted at 600 cents since B4 is 6 semitones above $\mathrm{F} 4$.

The f0 contours shown in Figure 2 can be referenced to the score in Figure 1 to ascertain which note is which and, therefore, the word being sung to each note. 


\section{Chorister NZKM (aged 17 at last recording):}

In chorister NZKM's May 1999 recording, there is considerable variation in f0 in each individual note; sometimes this is over one semitone. For the subsequent three f0 plots, her individual notes have steadier f0 contours year-on-year, and that for June 2004 (aged 17) is the steadiest of all. In addition, there is considerable overshoot at the starts of notes resulting in inaccurate onsets of pitches in the May 1999 recording and to an increasingly lesser degree in the later recordings, indicating improving note onset pitch accuracy. There remain initial pitch instabilities at note onsets and offsets in the later recordings, but these relate to consonant onsets (see below).

The second note starts for the word "truth" starts with a voiceless alveolar plosive followed by a voiced alveolar approximant. Any closure in the vocal tract between vowels during continuous singing has the potential to pull the f0 to a lower value unless this is compensated for and is normally something that improves with experience. In these four examples, there are two (the $1^{\text {st }}$ and $3^{\text {rd }}$ ) that exhibit a break in the f0 contour, whilst the other two examples have no such break. Having no break implies that the alveolar plosive has been changed from voiceless to voiced (/d/ instead of $/ \mathrm{t} /$ ) - a choral technique that is very appropriate for legato and for sostenuto - almost more crucially and pitch continuous singing of a phrase. It is also noteworthy that the $2^{\text {nd }}$ recording has rapid f0 fluctuations at the end of the first note and at the start of the second note. These are a result of the $/ \mathrm{r} /$ being sung as a rolled $/ \mathrm{r} / \mathrm{-a}$ technique that is commonly employed in this choir. The $4^{\text {th }}$ recording exhibits a clean well-defined $\mathrm{f} 0$ transition between these two notes.

Following the word "truth" is "of", and in the $1^{\text {st }}$ recording, these are sung as two clearly separated notes whereas in the other three recordings, there is no break between these two notes. The next word is " $G o d$ " on the $4^{\text {th }}$ and $5^{\text {th }}$ notes, and the $/ \mathrm{g} /$ is sung with a break in the f0 contour, but this break becomes less marked over time, which likely relates to attempts to make the sung line more legato by shortening the hold stage of the $/ \mathrm{g} /$ to reduce the airflow reduction and hence f0 drop. The next word is "the", which in speech would be fully voiced. For these four sung versions, a breath is taken just before this "the" in all but the $4^{\text {th }}$ version, suggesting the development of both enhanced breath control and a sense of musical phrasing that is more appropriate to performance of this particular line.

The second "God" is stressed and the voiced velar plosive /g/ narrows and there f0 drops during the /g/ followed by an upward unstable portamento in f0 to the note itself as the vowel starts. An unstable portamento is visible in all four plots; in the first, there is a complete break. This unstable portamento is least marked in the final recording, suggesting that attention is being paid to the musical phrasing of a legato line that is in keeping with what can be observed for the remainder of the phrase.

The remainder of the phrase is "of love', and in all cases, there is an f0 join visible at the start of both notes for the final three recordings; the first recording continues with small breaks between notes. In this case, there is a voice alveolar plosive at the end of the word "God" and a voice lateral approximant at the start of the word "love". There is an f0 overshoot during the lateral semivowel - a sound where the vocal tract is only partially constricted - probably due to an over-compensation being made for the lateral, which lessens by the fourth recording. 
In terms of tuning, observation of individual notes in the phrase across the recordings indicates that they are not close to their scored pitches in the first three recordings, but they are in the fourth. In addition, there is evidence of pitch gliding at the start of some notes, especially for the first three recordings in the second 'the', which is cleanly placed.

\section{Chorister MJRM (aged 18 at last recording):}

Overall, comparison of chorister/ex-chorister MJRM's recordings with those of chorister NZKM suggests that MJRM is not as well advanced in pitch control by the final recording, even though she was a year older. The pitching deviations during individual notes are wider and more irregular in the final recording compared to the final recording for NZKM in May 2006. There is no reason to suppose that development of such skills is directly related to age. However, in the context of comparing trends over the four MJRM recordings, it is clear that there is evidence of increased pitch control and accuracy along with less pitch variation during individual notes. Again, there is evidence of a reduction in $\mathrm{f} 0$ unstable portamento at note onsets over time.

Here again there is evidence of a rolled /r/ sound at the start of the second note for the word "truth" which appears more marked in the final recording; it has already been noted that this is a characteristic of the pronunciation of $/ r /$ in this choir. At the end of the word "truth" there is a voiceless fricative which all three choristers sing as voiced (a common technique commensurate with singing a legato line), but in this case unlike the other two choristers, all four recordings exhibit a drop in f0 most likely due to not compensating with an upward shift in pitch for the partial vocal tract closure. In all four recordings there is a large pitch glide at the start of the word "God" which lasts a considerable time compared particularly with chorister FWAH. All four choristers exhibit this effect which relates to giving significant accent to the word.

In these four MJRM examples, there are two (the $1^{\text {st }}$ and $3^{\text {rd }}$ ) that exhibit a break in the f0 contour and two other that have no break. Having no break implies that the alveolar plosive has been changed from voiceless to voiced (/d/ instead of $/ \mathrm{t} /)-\mathrm{a}$ choral technique that is very appropriate for legato and for sostenuto and pitch continuous singing of a phrase. It is also noteworthy that the $2^{\text {nd }}$ recording has rapid fo fluctuations at the end of the first note and at the start of the second note. These are a result of the $/ \mathrm{r} /$ being sung as a rolled $/ \mathrm{r} /$; a technique that is commonly employed in this choir. In contrast, the $4^{\text {th }}$ and final recording exhibits a clean well-defined f0 transition between these two notes.

As was the case for chorister NZKM, a breath is taken just before the "the" after "God" in all but the $4^{\text {th }}$ recording, even though the pitch contour rises over a semitone during the "the" in the fourth recording, suggesting a tuning compensation along with a more enhanced breath control and musical phrasing. During the second half of the phrase, the pitching is generally smoother than that in the first half of the phrase and each individual note remains steadier in pitch in her later recordings.

\section{Chorister FWAH (aged 15 at last recording):}

Chorister FWAH, who is the youngest of this group, generally exhibits smoother f0 
contours in all her recordings compared to those for the other two participants. There is less unstable portamento in pitch, the complete song line is sung as a single phrase in three of the four recordings (it may well be that she has made a musical choice on the third occasion to sing two separate lines).

Unlike the other two choristers, FWAH exhibits little f0 variation during the first consonant cluster in the first "truth", but in her final recording, f0 variation seems to overcompensate during the previous "the", which unusually falls by around half a semitone. On the first "God" in the phrase, her unstable portamenti are extremely rapid compared with the other two choristers and indeed non-existent in the third recording, resulting in a lesser accent.

In the second half of the sung phrase, an unstable portamento appears for the second "God" and the next word "of" in here October 2001 recording which is not apparent in her other three recordings. We would suggest that these are likely to relate to musical performance judgements that are being made 'in the moment'. This chorister also exhibits a clean vibrato in the last note which becomes more even over time; a skill that is not apparent to this extent for either of the other two choristers in their recordings. This may be a more innate approach to singing, the result of greater previous exposure to professional singing and/or singing training.

\section{Development of sound modifier control in the female choir voice}

The sound modifiers form an integral part of the human voice production mechanism and, in the context of singing, there is an expectation that choir members listen to each other and modify their sung pitch (sound source) as well as their timbre (sound modifiers) in a manner that is appropriate to their contribution to the overall choral sound. This is something of a 'balancing act', since the output sung sound is a combination of the sound source being changed acoustically by the sound modifiers and either of these can be responsible for changes in the perceived output. In addition, the overall output in terms of its spectral slope can be modified by changes in overall intensity [29].

The main aspect that is controlled by the sound modifiers during speech and singing is the sound of the language - the vowels and consonants. This we learn early in life, but the individual sounds are not identical from speaker to speaker, even within one language, since there are regional and individual accent variations. In choral singing, the overall sound of a choir changes greatly if, for example, the vowels produced by individual singers are not closely matched. This matching is often referred to as choral 'blend', and it makes a clearly perceivable difference to the overall sound of a choir and its perceived quality if singers match their sounds well or not. In terms of technique, the main requirement for good choral blend is the ability to hear each other well, an efficient and effective singing ability and good listening skills on the part of each singer, supported by peers and the conductor in learning to make appropriate self-corrections.

For the developing singer, especially during voice change, these listening skills are particularly important as they come to terms with the sound of their new voice as physical and related acoustic vocal change advances. Although less is usually stated 
about sound modifier control, it is a critical aspect of a singer's skill if they are to contribute professionally to the overall choral blend of their choir.

In acoustic terms, an analysis that is commonly applied is the long-term average spectrum (LTAS), such as those shown in Figure 3 for the same recordings for which f0 tracks are plotted in Figure 2. An LTAS enables the distribution of energy with frequency to be observed for an acoustic signal, in this case a sung line of a carol. Change over time can be observed in Figure 3, where each chorister's individual LTAS plots for the four recordings are clearly different, particularly in the $3-4 \mathrm{kHz}$ region. Acoustically, vowels are distinguished essentially by the frequency positions of the lowest two acoustic resonances of the vocal tract, seen on the LTAS as the first and second formants, or F1 and F2. The first and second formants are typically found in the frequency region below $2,250 \mathrm{~Hz}$ [28].

The frequency positions of the higher formants (F3, F4, F5 ...) in the region above 2.5 $\mathrm{kHz}$ relate to the overall timbre or quality of the perceived sound, and this is a particular factor in singing in terms of the overall quality of the voice and how it blends in with other singers in the context of choral singing. Changing the shape and volume of the epilarynx tube particularly affects the frequency positions of F3, F4 and F5. This can result in an enhanced overall acoustic resonance peak in the $2.5 \mathrm{kHz}$ to 4 $\mathrm{kHz}$ region that is referred to as the "singers' formant" or more commonly as the "singers' formant cluster"; a clustering of the $3^{\text {rd }}, 4^{\text {th }}$ and $5^{\text {th }}$ formants $[30,31]$. Trained tenors have been shown to have a second energy peak in the $8-9 \mathrm{kHz}$ region in addition to the singer's formant cluster in the $3 \mathrm{kHz}$ region that has been attributed to the second acoustic resonance of the epilarynx tube [32]. In the context of children's singing voice, evidence suggests that the perceived 'ring' relates to their singer's formant cluster around $4 \mathrm{kHz}$ (higher in frequency than that for adults since their epilarynx tube dimensions are smaller), and a strong second acoustic epilarynx tube peak in the $7.5-11 \mathrm{kHz}$ region that may be the main acoustic cue to the perception of 'ring' [33]. It is also worth noting the acoustic effect of the piriform fossae, which are located just above the oesophagus. They act to help define perceptually the upper frequency margin of the singer's formant cluster by adding an acoustic anti-resonance in the $4-5 \mathrm{kHz}$ region [34].

In a choral context, solo-type projection is usually something that is typically considered to be rather inappropriate, since it can result in individual voices standing out from the overall sound of the choir in a very obvious manner. In a solo singing context, the ability to project the voice is important, especially when microphones are not being used, but even then it must be employed with musical sensitivity. Many soloists are able to control the degree of projection in an appropriate manner, related to context, enabling them to contribute to performances as both solo and choral singers as required. The ability to make this change is something that emerges with listening, guidance from singing teachers and conductors, and experience. In the context of cathedral choir singing, choristers are guided to produce a projected sound appropriate to leading worship in a large building. Of particular importance in this context are uniform vowel sounds and well-formed consonants in a manner that is appropriate for the acoustics of the buildings in which the choir is performing.

In the context of choral singing in general, the issue of the overall quality of the choral output is extremely important and something that is usually worked on 
explicitly during rehearsals with the objective of guiding towards a good overall 'ensemble' or 'energised' sound. For individual singers, the change in overall spectral shape in the frequency region above $2.4 \mathrm{kHz}$, the timbral region, will relate to the extent to which that individual's singing voice will stand out within the overall choral sound and the degree to which that singer can blend in with other voices. The physical position of individual members of the choir relative to other members can have a significant effect on the overall voice line and therefore the total acoustic output from the choir $[35,36]$. Attention paid to this aspect through voice matching and physical placement of individual singers provides a practical means of taking advantage of this effect in practice.

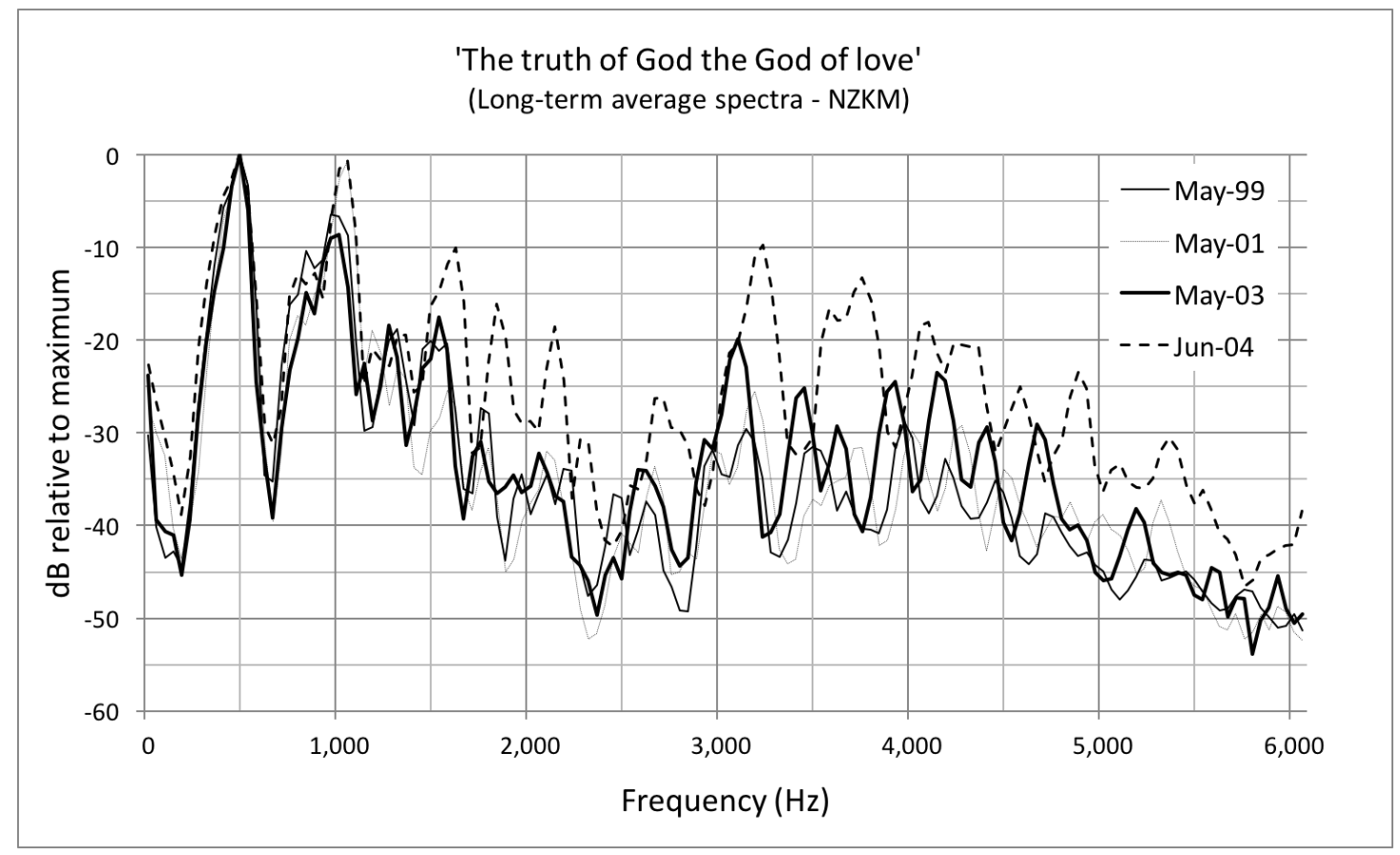



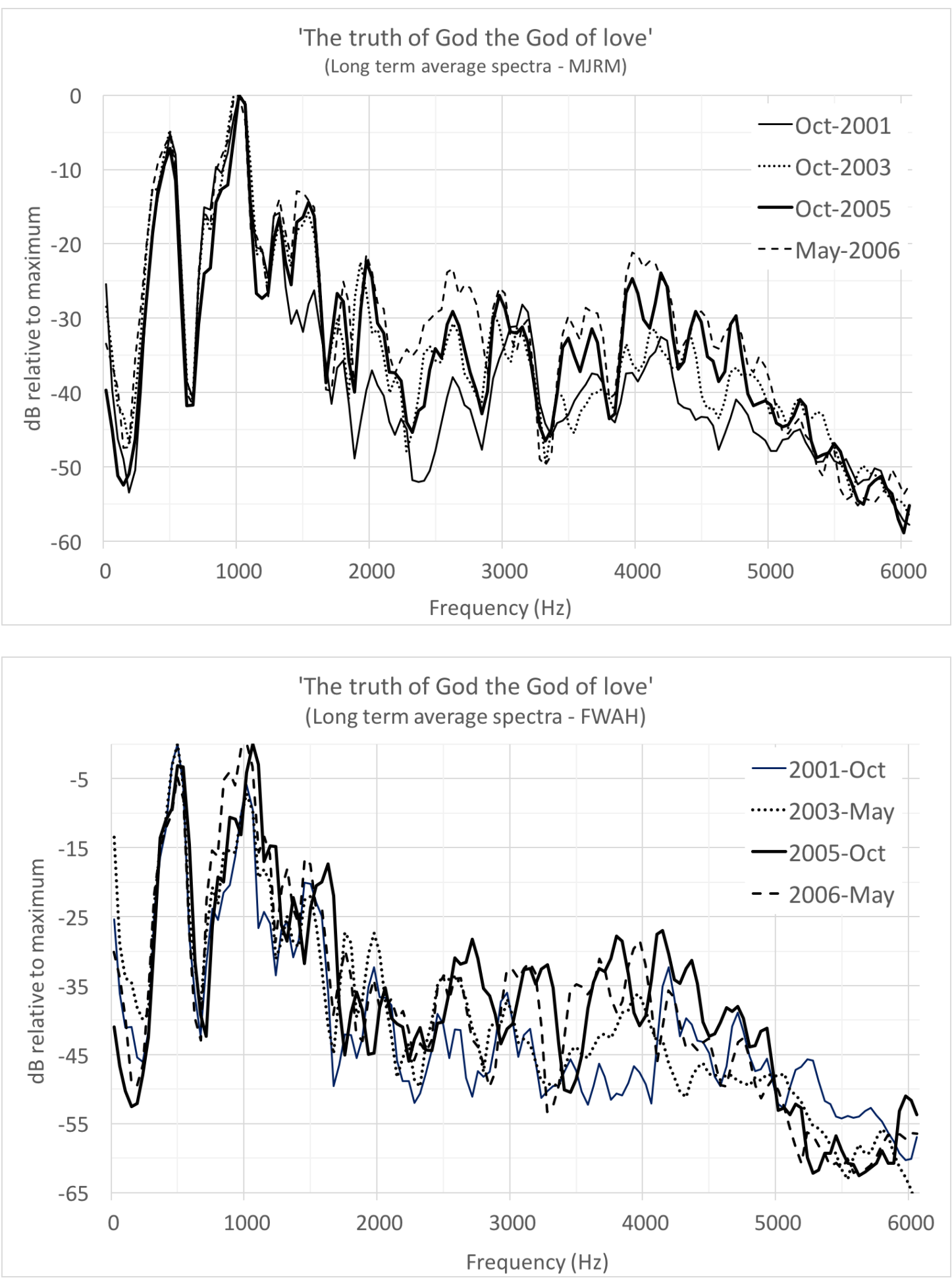

Figure 3: Long-term average spectra (LTAS) for four sung renderings by three individual girl cathedral choristers of 'the truth of God the God of love' (the second line of the carol 'This is the truth from above'). Note that all four plots are normalised with their highest amplitude peak being fixed at $0 \mathrm{~dB}$ to enable differences in the spectral slopes between the LTAS plots to be observed. 
Figure 3 shows that all three choristers are indeed able to control the degree of change in the timbral spectral regions. Here, long-term average spectra (LTAS) for the same four renderings considered in Figure 2 by each girl cathedral chorister of 'the truth of God the God of love' (the second line of 'This is the truth from above') are plotted for the four recordings for each chorister. The highest amplitude peak has been normalised for all four plots to $0 \mathrm{~dB}$ to enable direct comparison of spectral variation.

For all three choristers there is considerable change in spectral variation for this sung phrase, particularly in the $2.5-4 \mathrm{kHz}$ region; the timbral region. This is highly indicative of changes being made in the epilarynx area that relate to vocal projection. Little major spectral variation is observed in the lower frequency region where the first three formants change as a result of vowel production, something that is expected since the vowels are specified by the words of this second line of the carol. There is evidence that the overall spectral slope in this lower frequency region is very much flatter for chorister NZKM in her final (June 2004) recording, but we notice that the frequency positions of the formant peaks remains similar to the earlier recordings, as would be expected.

This provides direct evidence of a developing singing skill in the context of singing regular daily rehearsals, often supported by individual singing lessons in the school, as well as cathedral sung services approximately every other day. Direct evidence of vocal development is also shown in the singer's formant cluster or timbral region in terms of the difference between the earliest and latest recordings for each chorister, where there is considerable difference in the peaks between the recordings themselves across examples.

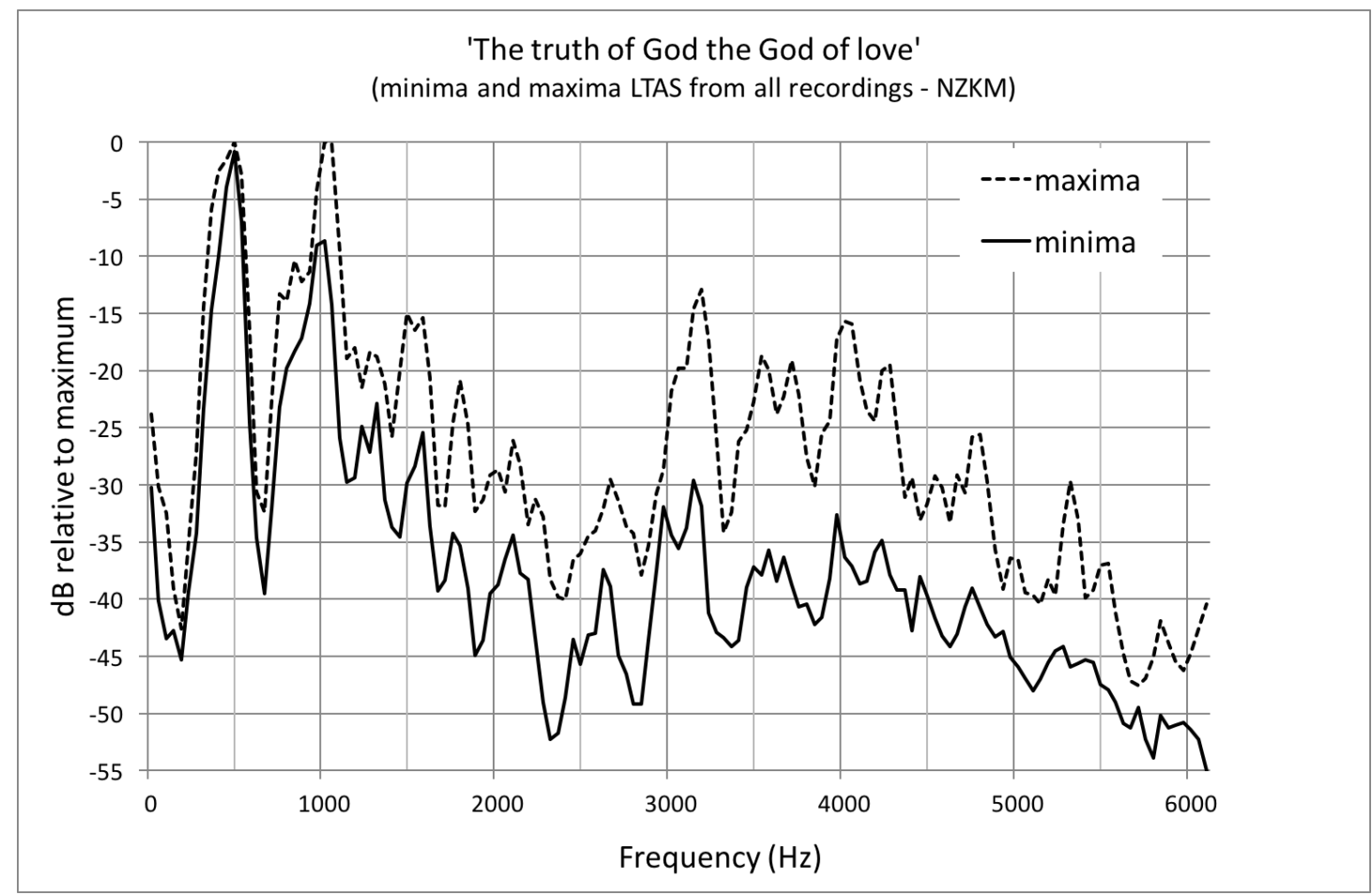



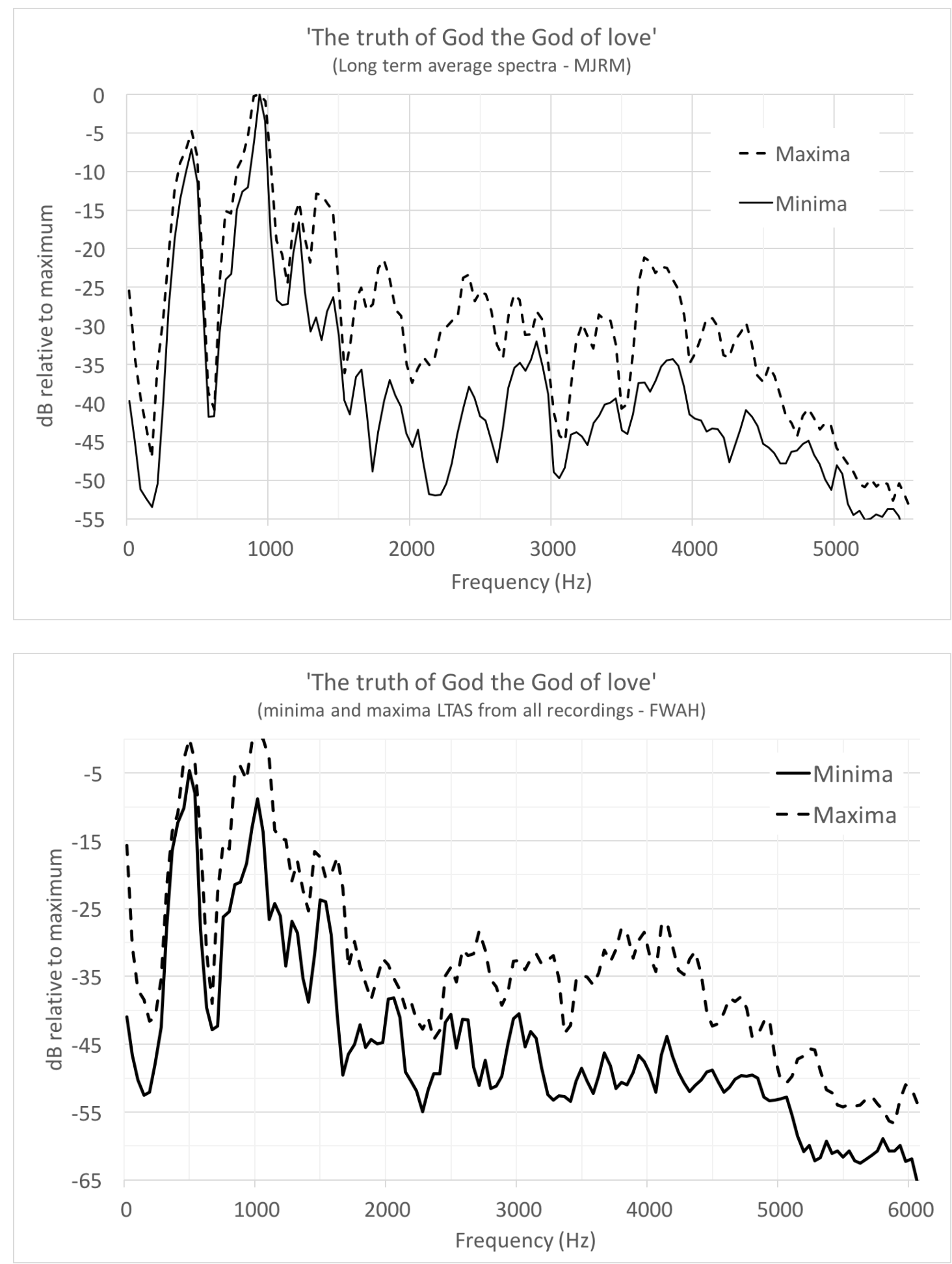

Figure 4: Plot of the minimum and maximum values from the long-term average spectra (LTAS) shown in figure 3 for all sung renderings of the second line of 'This is the truth from above' by each of three girl cathedral choristers.

In order to provide a clear picture of the potential that these choristers have for modifying their sung outputs across all their recordings, the overall minimum and maximum values from the all four LTAS plots for each chorister (plotted in Figure 3) that encompass all four sung renderings by each the three girl cathedral choristers of 
'the truth of God the God of love' (the second line of 'This is the truth from above') are presented in Figure 4. Once again, the plots have been normalised such that the lowest peaks are set to $0 \mathrm{~dB}$ to enable comparison of spectral slope variation between the plots. Here it can be seen that there is a huge variation evident in the timbral region between the minimum and maximum values achieved by each of the three girl choristers across the overall time period covered by their four recordings and that, in some frequency regions, this difference is greater than $15 \mathrm{~dB}$.

Overall, these differences in spectral slope between the four recordings for each chorister suggest that the experiences gained by these choristers singing regularly and professionally within a close-knit choral context have enabled the establishment of a very significant degree of vocal control, not only in terms of word pronunciation, but also in overall timbral control of their vocal outputs. It remains to be explored what they do individually when singing within the choir since these recordings were individual renderings of a carol and, therefore, more akin to singing as a soloist, albeit in a slightly unusual situation.

\section{Conclusions}

The overall in-tune and overall sound of a choir requires sensitive musical input that is based on individual critical listening and musical singing performance from each and every member of that choir under the guidance of the choir trainer/conductor - it is often the case that individual singers cannot hear their own sung output to enable them to judge its appropriateness. These two aspects of choral singing are often rather neglected in terms of detailed research work, and yet they are probably the most critical in terms of the providing an exceptional and noteworthy overall audience listening experience.

This article has considered the developing choral singing voice of three girl choristers in an English Cathedral Choir over a number of years. It has demonstrated their changing abilities in singing pitch control over this period, as illustrated by fundamental frequency plots over time. These have shown improvements in tuning, control of note onsets, improvements over time with regard to appropriate pitch control during sung consonants and the development of vibrato. In terms of choral blend, empirical data show that each develops considerable additional control over the output spectrum of their voices, particularly in what we describe as the timbral region (above $2.5 \mathrm{kHz}$ ). In particular for these girl choristers, the results suggest that the highly stimulating musical setting in which they find themselves $[11,37]$ is very conducive to encouraging a high degree of versatility in pitch and timbre control of their sung outputs - both vital aspects that underpin many of the main differences between the outputs of professional and amateur choirs.

\section{Acknowledgements}

The authors thank the choristers who took part in this study, as well as the staff at Wells Cathedral and Wells Cathedral School who made this study possible. 


\section{References}

[1] Arts Council. (2015). Taking Part 2014-15: Music. Retrieved from http://www.artscouncil.org.uk/document/taking-part-profile-report-music201415

[2] Geisler, U. \& Johansson, K. (2015). Contemporary Concepts and Practices of Choral Singing. In G.F. Welch, D.M. Howard, \& J. Nix (Eds). Oxford Handbook of Singing. Published online DOI: 10.1093/oxfordhb/9780199660773.013.31

[3] Fisher, J., Kayes, G., \& Popeil, L. (2014). Pedagogy of Different Sung Genres. In G.F. Welch, D.M. Howard, \& J. Nix (Eds). Oxford Handbook of Singing. Published online DOI: 10.1093/oxfordhb/9780199660773.013.005

[4] Nix, J. (2015). Systematic Development of Vocal Technique. In G.F. Welch, D.M. Howard, \& J. Nix (Eds). Oxford Handbook of Singing. Published online DOI: 10.1093/oxfordhb/9780199660773.013.001

[5] Hoppe, D., Sadakata, M., \& Desain, P. (2006). Development of real-time visual feedback assistance in singing training. Journal of Computer Assisted Learning, 22, 308-316.

[6] Nair, G., Howard, D.M., and Welch, G.F. (2018). Practical voice analyses and their application in the studio, In G.F. Welch, D.M. Howard, \& J. Nix (Eds). Oxford Handbook of Singing.

[7] Fitch, W.T., \& Giedd, J. (1999) Morphology and development of the human vocal tract using magnetic resonance imaging. Journal of the Acoustical Society of America, 106(3), 1511-1522.

[8] Howard, D.M., and Murphy, D.T. (2009). Voice science acoustics and recording, San Diego: Plural Press.

[9] Watson, A. (2014). Breathing in Singing. In G.Welch, D.Howard \& J. Nix (eds). The Oxford Handbook of Singing (forthcoming). Online chapter publication, October 2014. DOI: 10.1093/oxfordhb/9780199660773.013.10

[10] Howard, D.M. (2015). Choral singing and healthy voice production, Tunbridge Wells: Willow Leaf Publishing.

[11] Harrison, S.D. Welch G. F. \& Adler, A. (Eds). (2012). Perspectives on Males and Singing. Dordrecht: Springer. DOI 10.1007/978-94-007-2660-4

[12] Toole, G. (2003). The Female Singing Voice from Childhood through Adolescence. Unpublished $\mathrm{PhD}$, University of North Carolina at Greensboro.

[13] Gackle, L. (2014). Adolescent Girls' Singing Development. In G.F. Welch, D.M. Howard, \& J. Nix (Eds). Oxford Handbook of Singing. Published online DOI: 10.1093/oxfordhb/9780199660773.013.22

[14] Rogers, D.J., Setlur, J., Raol, N. Maurer, R., and Hartnick, C.J. (2014). Evaluation of true vocal fold growth as a function of age, Otolaryngology Head and Neck Surgery, 15(4) 681-686 DOI: 10.1177/0194599814547489

[15] Stathopoulos, E.T., Huber, J.E., \& Sussman, J.E. (2011). Changes in Acoustic Characteristics of the Voice Across the Life Span: Measures from Individuals 493 Years of Age. Journal of Speech, Language and Hearing Research, 54, 1011-1021.

[16] Kahane, J.C. (1978). A morphological study of the human prepubertal and pubertal larynx, Am. J. Anat., 151, 11-20.

[17] Welch, G.F. (2005). Singing as Communication. In D. Miell, R. MacDonald \& D. Hargreaves (Eds.), Musical Communication. (pp. 239-259). New York: Oxford University Press. 
[18] Welch, G.F. (2009). Evidence of the development of vocal pitch matching ability in children. Japanese Journal of Music Education Research, 39(1), 38-47

[19] Welch, G.F. (2016). Singing and Vocal Development. In G. McPherson (Ed.), The Child as Musician: A Handbook of Musical Development. $2^{\text {nd }}$ Edition. (pp. 441-461). New York: Oxford University Press.

[20] Wise, K. J. \& Sloboda, J. A. (2008). Establishing an empirical profile of selfdefined 'tone deafness': Perception, singing performance and selfassessment. Musicae Scientiae, 12, 3-23

[21] Anderson, S., Himonides, E., Wise, K., Welch, G., Stewart, L. (2012). Is there potential for learning in amusia? A study of the effect of singing intervention in congenital amusia, Ann. NY Acad. Sci., 1252, 345-53. doi: 10.1111/j.17496632.2011.06404.x.

[22] Dalla Bella, S., Giguere, J. F., \& Peretz, I. (2007). Singing proficiency in the general population, Journal of the Acoustical Society of America 121, (2), 11821189.

[23] Welch, G.F. (2011). Culture and gender in a cathedral music context: An activity theory exploration. In M. Barrett (Ed.), A Cultural Psychology of Music Education. (pp. 225-258). New York: Oxford University Press.

[24] Laven, M. (2002). Virgins of Venice. London: Viking/Penguin.

[25] Mould, A. (2007). The English Chorister: A History. London: Hambledon Continuum.

[26] Sackett, E., \& Skinner, J. (2006). Abbeys, Priories and Cathedrals. Salisbury: The Francis Frith Collection.

[27] Owens, M., \& Welch, G.F. (2017). Choral Pedagogy and the Construction of Identity: Girls. In F. Abrahams, \& P.D. Head (Eds.), Oxford Handbook of Choral Pedagogy. (pp 167-181) New York: Oxford University Press. DOI: 10.1093/oxfordhb/9780199373369.013.9

[28] White, P., (2009). A study of the effects of vocal intensity variation on children's voices using long-term average spectum (LTAS) analysis. Log Phon Voc, 23, 111-120.

[30] Baken, R.J., and Orlikoff, R.F. (1999). Clinical measurement of speech and voice, San Diego: Singular Publishing Group.

[31] Sundberg, J. (1987). The science of the singing voice, Dekalb: Northern Illinois University Press.

[30] Sundberg J (1974) Articulatory interpretation of the " singing formant'”. Journal of the Acoustic Society of America, 55, 838-844.

[32] Titze IR, Jin SM. (2003). Is there evidence of a second singer's formant? $J$ Singing, 59, (4), 329-331.

[33] Howard, D.M., Williams, J., and Herbst, C. (2014). "Ring" in the solo child singing voice, Journal of Voice, 28, (2), 161-169.

[34] Delvaux, B., and Howard, D.M. (2014). A new method to explore the spectral impact of the piriform fossae on the singing voice: Benchmarking using MRIbased 3D-printed vocal tracts, PLOS ONE, 9, (7), 1-15.

[35] Daugherty, J.F. (1999). Spacing, formation, and choral sound: Preferences and perceptions of auditors and choristers. Journal of Research in Music Education, 47, 224-238. doi: 10.2307/3345781

[36] Daugherty, J.F., Manternach, J.N., \& Brunkan, M.C. (2013). Acoustic and perceptual measures of SATB choir performances on two types of portable riser units. International Journal of Music Education 31 (3), 359-75. 
[37] Welch, G.F. (2007). Addressing the multifaceted nature of music education: an activity theory research perspective. Research Studies in Music Education, 28, 23-38 